\title{
PSICOLOGIA E INCLUSÃO SOCIAL DE ALUNOS COM DEFICIÊNCIA: A ATUAÇÃO DO PSICÓLOGO NA EDUCAÇÃO INCLUSIVA
}

\author{
PSICOLOGÍA E INCLUSIÓN SOCIAL DE ESTUDIANTES CON DISCAPACIDADES: \\ EL DESEMPEÑO DEL PSICÓLOGO EN EDUCACIÓN INCLUSIVA
}

\section{PSYCHOLOGY AND SOCIAL INCLUSION OF STUDENTS WITH DISABILITIES: THE PSYCHOLOGIST'S ROLE IN INCLUSIVE EDUCATION}

\author{
Fabiana Darc MIRANDA ${ }^{1}$ \\ Eveline Borges Vilela RIBEIRO ${ }^{2}$
}

\begin{abstract}
RESUMO: Nos últimos anos temos acompanhado a crescente preocupação da psicologia com a educação. Assim, a atuação do Psicólogo Escolar/Educacional, no âmbito da educação se resume em trabalhos múltiplos, desde a realização de pesquisas, diagnósticos e intervenções preventivas em grupo e individualmente. Nesse sentido, objetiva-se com esse estudo, identificar como se dá a atuação do psicólogo escolar no âmbito da educação inclusiva em um município do interior de Minas Gerais. Realizamos, portanto, uma pesquisa de campo com cinco psicólogas que atuam no âmbito escolar da rede municipal de ensino. As psicólogas responderam a um questionário estruturado que abordava o papel do psicólogo na educação inclusiva bem como suas formas de atuação. $\mathrm{Na}$ análise dos dados, descrevemos e discutimos o material empírico coletado por meio das entrevistas e por fim, nas considerações finais, ressaltamos as contribuições da psicologia escolar para a inclusão das pessoas com deficiências nas escolas, indicando que o trabalho desse profissional deve abranger desde os alunos, os familiares, até a equipe escolar.
\end{abstract}

PALAVRAS-CHAVE: Educação inclusiva. Deficiência. Psicologia. Escola.

RESUMEN: En los últimos años hemos seguido la creciente preocupación de la psicología con la educación. Así, el desempeño del psicólogo escolarleducativo en el contexto de la educación se resume en múltiples obras, desde la realización de investigaciones, diagnósticos $e$ intervenciones preventivas en grupos e individualmente. En este sentido, este estudio pretende identificar cómo el desempeño del psicólogo escolar en el contexto de la educación inclusiva se da en un municipio en el interior de Minas Gerais. Por lo tanto, realizamos una investigación de campo con cinco psicólogos que trabajan en el área escolar de la red de Educación Municipal. Los psicólogos respondieron a un cuestionario estructurado que aborda el papel de los psicólogos en la educación inclusiva, así como sus formas de acción. En el análisis de los datos, describimos y discutimos el material empírico recolectado a través de las entrevistas y finalmente, en las consideraciones finales, enfatizamos las

\footnotetext{
${ }^{1}$ Universidade Federal de Góias (UFG), Jataí - GO - Brasil. Mestranda em educação. Pesquisadora na área de educação inclusiva, inclusão escolar e psicologia educacional e escolar. ORCID: <https://orcid.org/0000-00031680-4081>. E-mail: fabyana.darc@gmail.com

${ }^{2}$ Universidade Federal de Góias (UFG), Jataí - GO - Brasil. Professora da Universidade Federal de Goiás / Regional Jataí. Doutora em Química (2015) pela Universidade Federal de Goiás. E-mail: fabyana.darc@gmail.com
} 
contribuciones de la psicología escolar a la inclusión de personas con discapacidades en las escuelas, indicando que el El trabajo de este profesional debe cubrir de los estudiantes, parientes, al equipo de la escuela.

PALABRAS CLAVE: Educación inclusiva. Deficiencia. Psicología. Escuela.

ABSTRACT: In recent years we have been following the growing concern of psychology with education. Thus, the performance of the School / Educational Psychologist in the scope of education is summarized in multiple works, from research, diagnosis and preventive interventions in group and individually. In this sense, the purpose of this study is to identify how the performance of the school psychologist in the scope of inclusive education in a municipality in the interior of Minas Gerais. We conducted, therefore, a field research with five psychologists who work in the school context of the municipal school network. The psychologists answered a structured questionnaire that addressed the psychologist's role in inclusive education as well as their forms of action. In the analysis of the data, we describe and discuss the empirical material collected through interviews and finally, in the final considerations, we highlight the contributions of school psychology to the inclusion of people with disabilities in schools, indicating that the work of this professional should cover students, family members, even the school staff.

KEYWORDS: Inclusive education. Deficiency. Psychology. School.

\section{Introdução}

Inicialmente, procuramos realizar um levantamento de dados sobre a temática pesquisada por meio de uma pesquisa bibliográfica, para obtermos maiores informações sobre o assunto em questão.

A pesquisa bibliográfica é definida como um conjunto de escritos que dissertam acerca dos principais estudos científicos que já foram realizados sobre a temática escolhida, e que ao mesmo tempo, tem valor relevante por fornecerem informações atuais e importantes sobre determinado assunto. Este tipo de pesquisa compreende: publicações avulsas, livros, jornais, revistas, vídeos, internet, dentre outros. Esta forma de pesquisa pode ser realizada tanto isolada, por meio de análise de documentos, ou como complementar a uma pesquisa de campo, que é o caso em questão, todavia em ambos os casos fornece uma estrutura de trabalho fidedigna. (LUNA apud BONI; QUARESMA, 2005)

Na visão de Becker, citado por Boni e Quaresma (2005), qualquer estudo, pesquisa ou trabalho que envolva temas sociais, deve ser fundamentado por um arcabouço teórico, que informa as escolhas do pesquisador em relação ao tema proposto, sendo, portanto, fundamental na elaboração de um trabalho acadêmico. 
Como muitos dados não podem ser obtidos apenas por meio da pesquisa bibliográfica, realizamos uma coleta de dados a partir da aplicação de entrevistas. Trata-se, segundo Haguette (1997, p. 86) de um "processo de interação social entre duas pessoas na qual uma delas, o entrevistador, tem por objetivo a obtenção de informações por parte do outro, o entrevistado". A entrevista é, ainda, uma das técnicas mais utilizadas quando se trata de trabalhos de campo (BONI; QUARESMA, 2005).

Utilizamos, portanto, como coleta de dados, as entrevistas estruturadas. Este tipo de entrevista consiste em elaboração prévia de perguntas, denominado em alguns casos de questionários (BONI; QUARESMA, 2005). É relevante dizer que a entrevista estruturada, também denominada em alguns casos de questionário, é a principal forma de coletar dados em alguns tipos de pesquisa, a saber: pesquisas eleitorais, de opinião, no censo, para coletar dados para o Instituto Brasileiro de Geografia e Estatística; dentre outras. (BONI; QUARESMA, 2005)

O roteiro foi estruturado em torno das questões que entendemos ser essenciais para a compreensão do trabalho do psicólogo no âmbito da educação inclusiva. Foi necessário utilizar os roteiros estruturados em função do tempo disponível para realização deste estudo e da intenção de evitar o acúmulo de material empírico que não conseguiríamos tratar de modo suficiente, caso tivéssemos utilizado uma entrevista não estruturada. Apesar de sua limitação, as entrevistas estruturadas possibilitaram uma comparação entre as várias respostas, seguindo um padrão comum, uma vez que as diferenças acontecem nesse tipo de entrevista apenas nas respostas e não na formulação das questões (LAKATOS, 1996).

Assim, de acordo com Boni e Quaresma (2005), é possível dizer que a entrevista estruturada também possui algumas vantagens. Uma delas, na visão dos autores, se resume na facilidade de aplicação dos questionários, uma vez que não é obrigatória a presença do pesquisador para a aplicação; e ainda, as questões podem ser aplicadas a um maior número de amostras ao mesmo tempo, de modo que pode ser trabalha com quantidades maiores de amostragens, dependendo da pesquisa a ser realizada. A entrevista estruturada permite um sigilo maior em relação às respostas, dando abertura ao entrevistado, sendo ainda uma forma de entrevista rápida e precisa nas respostas dos entrevistados. (BONI; QUAREMA, 2005)

\section{Metodologia}

Nesse sentido, foram entrevistas cinco psicólogas com idade entre 34-52 anos. Em relação ao tempo de experiência na profissão, temos os seguintes dados: uma de 12 anos de 
experiência, outra de 16 e 17 anos e as mais novas com 2 anos e 6 meses e outra de 6 meses de exercício na profissão. A formação varia, uma delas tem mestrado na área da educação, e outras três possuem pós-graduação também na área da educação, apenas uma não possui especialização. Ao longo do texto, utilizaremos as siglas P1, P2, P3, P4 e P5 para nos referirmos a cada uma das entrevistadas.

As psicólogas entrevistadas trabalham no Centro Municipal de Atendimento Psicopedagógico - CEMAP, de Santo Antônio do Monte. O CEMAP é voltado para o atendimento e acompanhamento de crianças e adolescente que estudam nas escolas do município, e que necessitem de acompanhamento psicopedagógico.

Os atendimentos não acontecem nas escolas, estes acontecem no próprio estabelecimento do CEMAP, de maneira que as crianças e adolescentes devem se deslocar até este centro. As especialidades deste centro variam, incluindo, no seu quadro de pessoal: psicólogos, pedagogas, assistente social, fonoaudióloga, terapeuta ocupacional, e psicopedagogas, tudo para que a população possa ser atendida em todas as especificidades, de acordo com a sua necessidade e demanda. O CEMAP atende alunos disléxicos, dislálicos, hiperativos e desatentos, aqueles que apresentam problemas de aprendizagem de outra ordem, dificuldade na fala e ainda aqueles com deficiência, chamados na área da educação de alunos portadores de necessidades educativas especiais - N.E.E.

Ao realizar a análise dos dados, constatamos três aspectos que merecem atenção no que se refere à atuação desse profissional, a saber: o trabalho prático do psicólogo, o papel da família no trabalho do psicólogo escolar educacional e, por último, os limites e as possibilidades da atuação profissional. Entendemos que esses temas representam categorias importantes a serem discutidas neste capítulo, sem perder de vista as reflexões teóricas já feitas neste trabalho.

\section{O trabalho prático do psicólogo escolar}

Em um primeiro momento, ao serem questionadas sobre a existência ou não de demandas de alunos com deficiência, ou ainda portadores de necessidades educativas especiais, encaminhados pelas escolas, nessa instituição, as psicólogas, afirmam que existem bastante demanda, uma vez que a Associação de Pais e Amigos dos Excepcionais (APAE) quase já não atende mais a essa clientela, sendo a demanda encaminhada, quase em sua maioria, para o CEMAP. 
As crianças são recebidas pelo CEMAP, por meio de encaminhamentos que as próprias escolas realizam, ou ainda, por qualquer outro profissional do âmbito municipal. Como afirma uma das psicólogas entrevistadas, os alunos chegam à instituição: "através de encaminhamentos feitos pelas escolas municipais, juntamente com encaminhamento médico, quando o médico encaminha a criança." (P2)

Outra entrevistada relata, mais especificamente, como é a chegada dos alunos com deficiência na instituição, afirmando que "os alunos com deficiência são encaminhados à esta instituição através dos professores e especialistas das escolas municipais, uma vez detectadas as necessidades educacionais especiais de forma a garantir a participação de todos.” (P1)

Uma terceira entrevistada acrescenta que os encaminhamentos devem conter a exposição dos motivos pelos quais os alunos são dirigidos ao CEMAP. A propósito disso, P3 afirma que a demanda para acompanhamento psicológico dos alunos com deficiência se volta, sobretudo, para o fortalecimento da autoestima, pois, uma vez apresentando dificuldades de aprender, o aluno se sente, na maioria das vezes incapaz de prosseguir o aprendizado. Em suas palavras:

uma das principais demandas apresentadas pelos alunos que atendo está relacionada ao fortalecimento da autoestima, pois ao manifestar dificuldades para aprender, o aluno sente-se, muitas vezes, incapaz de prosseguir a sua caminhada escolar, neste sentido, pode indicar alterações em seu comportamento: isolamento, agressividade, desatenção, etc. Tornase essencial que o (a) psicólogo (a) escolar leve o aluno a re (pensar) e re (significar) o seu processo de aprendizagem para que se sinta capaz de aprender dentro do seu ritmo. (P3)

A psicóloga LGF pontua que

quando o aluno chega, ele é avaliado e encaminhado para a pedagogia, fonoaudióloga, terapia ocupacional, psicopedagogia, interprete ou professora da sala de recursos e Braille, para ser estimulado cognitivamente e ter suas potencialidades e habilidades desenvolvidas ou até mesmo descobertas. Quando necessário também são encaminhadas para o xadrez ou atividades físicas. Mas no trabalho clinico, trabalhamos questões familiares junto a assistente social, fortalecimento da autoestima, relacionamento interpessoal, através de jogos, brincadeiras, desenhos, histórias... (P4)

Em relação ao acompanhamento psicológico realizado pelas psicólogas, as entrevistadas afirmam que todos os alunos são acolhidos na instituição, juntamente com suas famílias. Os procedimentos adotados não variam, sendo que os encaminhamentos são 
analisados e, de acordo com a necessidade, realiza-se uma primeira entrevista com os pais dos alunos, denominada de "anamnese", como explica uma das entrevistadas:

a primeira atitude tomada é a entrevista de anamnese com os pais, Em seguida a criança inicia avaliação para verificar suas dificuldades $e$ potencialidades. Solicito relatório da escola, para verificar conduta do aluno e defasagens apresentadas. Como atendo crianças hiperativas e com déficit de atenção, procuro atividades que visam melhorar o funcionamento das áreas cerebrais afetadas. (P2)

Posteriormente, realiza-se uma avaliação do aluno a partir de uma entrevista com os pais e com e com os alunos, procurando colher dados a respeito da dinâmica familiar, o dia a dia crianças, as questões escolares dentre outras informações necessárias de acordo com o caso. Ainda, utilizam para tal avaliação a aplicação de alguns testes projetivos para iniciar o processo de psicodiagnóstico.

$\mathrm{Na}$ fala de uma das entrevistadas foi possível perceber que existe, ainda, nas escolas certo preconceito em relação à adaptação da criança. Enfatiza-se que ela é quem deve se adaptar a escola e não a escola a ela, sendo que a visão predominante é aquela de que o problema está no aluno, e muitas vezes não relacionado ao não querer aprender, tal perspectiva é voltada para problemas com a aprendizagem, e acompanhadas ainda, do famoso discurso médico, a presente afirma fica bastante clara na fala de uma das psicólogas:

as escolas acreditam que a criança que deve se adaptara escola e não ao contrário. Qualquer caso de problema COM a aprendizagem os educadores tentam um laudo para justificar a sua capacidade humana de ter dificuldade para ensinar, é como se, por exemplo, uma TDAH fosse sinônimo de incapacidade de aprender. $O$ médico diagnóstica, medica e a escola não precisa ensinar, pois ela, a criança, tem um transtorno que a impede de aprender. (P4)

As entrevistadas acrescentam que, após realizarem as anameses, é feito um psicodiagnóstico com a criança, visando colher dados acerca das queixas apresentadas, e assim, um trabalho com a criança é conduzido, com a finalidade de trabalhar e fortalecer os aspectos que foram diagnosticados nas entrevistas iniciais. Além disso, trabalha-se com a valorização de suas habilidades, com o estabelecimento de limites e regras. Serviços de caráter lúdico, de estimulação cognitiva e psicomotricidade são também oferecidos as crianças que deles necessitam.

Quando há necessidade, os pais são chamados para receberem um parecer dos acompanhamentos e, ainda, em alguns casos, certas orientações são necessárias para uma 
maior compreensão do caso. Segundo P5, ainda existe a possibilidade de realizar outros encaminhamentos, para profissionais específicos, quando a demanda ultrapassa os limites de atendimentos do CEMAP, por exemplo, nos casos de atendimento médico especializado: pediatria, neurologia e psiquiatria dentre outros

Uma das psicólogas, quando questionada a respeito da sua atuação no CEMAP, nas especificidades do atendimento ao aluno com deficiência, nos falam o seguinte:

minha atuação dá-se em conformidade com a demanda apresentada por cada aluno. Busco respeitar a particularidade de cada caso para que bons resultados possam ser obtidos. Sempre busco manter contato com a família do aluno e com a equipe da escola (supervisora e professora) e com os profissionais do CEMAP, caso o aluno realize mais de um atendimento especializado (o estudo do caso que está sendo atendido por mais de um profissional é essencial, pois assim, o aluno é visto de forma integral (...). (P3)

As psicólogas também asseguram aos seus pacientes atendimentos diversificados, indo além dos atendimentos propostos pelo CEMAP, abrangendo um atendimento multidisciplinar aos seus alunos, como nos mostra P3: “[...] se for necessário que o aluno seja atendido em outro setor, paralelamente, ao atendimento realizado no setor de psicologia, um encaminhamento interno é feito ao profissional do CEMAP [...]" (P3)

Buscando uma melhoria nos atendimentos prestados aos alunos, estas psicólogas se preocupam com a rede social na qual estas crianças estão envolvidas: escola, família, sociedade; e pensando em resultados positivos de seus trabalhos, realizam grupos com os pais para esclarecimentos sobre os trabalhos desenvolvidos e sobre as possibilidades e limites de cada criança, visando uma valorização do que cada uma delas tem para oferecer e desenvolver; trabalhos com os professores também são realizados, reuniões nas escolas estão sempre acontecendo, seja para esclarecimento, seja para orientações e capacitações dos profissionais envolvidos com a dinâmica da educação inclusiva, como ainda grupos de encontros com os pais das crianças atendidas. Uma das psicólogas afirma que:

trabalhar em uma equipe multiprofissional é muito bom (atualmente o CEMAP possui 05 psicólogas, 02 psicopedagogas, 02 fonoaudiólogas, 01 assistente social, 02 professoras alfabetizadoras, 01 professora da sala de recursos, 01 professor de xadrez) Sempre busco manter contato próximo com a família dos alunos que atendo. Busco estabelecer um vínculo sólido com a família para que possa ser percebida como alguém que está ali para ajudar e não apenas para apontar falhas. Quando há vontade, um caminho se abre rumo às mudanças necessárias, porém quando se há dedicação e 
persistência vários caminhos se abrem para o aluno. A parceria firmada entre o setor de psicologia e a família dos alunos resulta sempre na melhora do quadro apresentado [...] o apoio da família do aluno e da equipe da escola são ferramentas importantes durante o meu trabalho. (P3)

Para o desenvolvimento dos trabalhos e procedimentos nos atendimentos aos alunos com deficiências, a equipe troca informações entre si, sempre que surgem dúvidas quanto às condutas de cada caso, e se necessário buscam por capacitações na área para um melhor atendimento a estas crianças, como apontado nas falas que se seguiram,

Dentro do trabalho realizado, as psicólogas afirmam ainda que utilizam de alguns instrumentos psicológicos durante seus atendimentos, acompanhamentos e avaliações, como é o caso do uso de jogos e vídeos educacionais e psicológicos, bem como o uso de tecnologia assistivas:

[...] faz-se uma avaliação do aluno (psicodiagnóstico) usando alguns testes. Entre eles, estão: os testes projetivos (desenho de família, etc), o Bender e o Raven; hora do jogo [...] Se houver demanda de atendimento, o aluno será atendido em grupo ou individualmente conforme os objetivos a serem atingidos. Além da abertura de um bom espaço de escuta, jogos diversificados relacionados à expressão dos sentimentos, fortalecimento da autoestima, concentração, aceitação das regras, memorização, psicomotricidade, são usados durante os atendimentos. Tudo que será usado durante os atendimentos é escolhido conforme as necessidades reais do aluno. Usa-se, também, o notebook (CD e DVD com jogos e vídeos educacionais e psicológicos) As tecnologias assistivas acessiveis (teclado livre, cartas enigmáticas, dosvox, áudio- livro, etc são usadas em conformidade com a demanda apresentada pelo aluno). (P3)

Um ponto importante que foi citado por uma das psicólogas foi a mistura dos termos "dificuldade de aprendizagem" e "dificuldade com a aprendizagem" por parte da escola. A mesma classifica os termos da seguinte forma:

dificuldade de aprendizagem: é quando a criança possui alguma lesão ou transtorno neurológico que a impeça de aprender; e dificuldade com a aprendizagem é quando a maneira de ensinar do educador não consegue atingir o educando dificultando assim, a aquisição de conhecimento, ou até mesmo impossibilitando o aprendizado. A famosa falta de didática. (P4)

Nesta fala fica evidenciado que algum dos problemas e das dificuldades encontrado pelos alunos pode estar na forma como o ensino lhes é passado e não focada, como em muitos casos, na suas deficiências. 


\title{
O papel da família no trabalho do psicólogo escolar
}

A família na visão de algumas das psicólogas entrevistada é de suma importância para o exercício de um trabalho eficaz no âmbito da educação inclusiva. Todas reforçam que sem a participação da família o trabalho não seria possível, afirmam que "a família deve participar ativamente do atendimento do filho, seguindo as orientações feitas pela psicóloga, com objetivo de auxiliar no progresso da criança”. (P2)

Afirmam ainda que os pais de seus pacientes, que são portadores de necessidades especiais e que frequentam ativamente a escola, têm papel ativo, e fazem o possível para que seus filhos sejam felizes "os meus três pacientes incluídos tem $100 \%$ de participação da família. Os pais não medem esforços para o bem estar e sucesso dos filhos incluídos, e o mais importante, não tem medo ou preguiça de buscar". (P4)

Já outra psicóloga, que possuí mais tempo de experiência na profissão, afirma que o papel dos familiares, em particular, dos pais, não é muito significativo, dizendo de uma visão negativa em relação a estes familiares, a família tem uma participação "muito pequena, às vezes, inexistente". (P1)

$\mathrm{Na}$ visão de outra psicóloga, é muito importante que os pais deem continuidade aos trabalhos realizados nos atendimentos, acompanhando em casa seus filhos "é importante que a família trabalhe lado a lado, pois o trabalho deve ser um conjunto, tudo que é feito na clínica deve ser reforçado em casa." (P5) e ainda

\begin{abstract}
o apoio da família é essencial, pois o aluno sente-se mais capaz e confiante durante as dificuldades que encontra em seu processo de aprendizagem. $O$ aluno ao sentir que possui o apoio da família entende que alguém se preocupa com ele; torce pelo seu sucesso. O apoio da família também é essencial em se tratando de novos encaminhamentos, aos setores tais como: neuropediatria , fonoaudióloga; etc. Se a família não demonstra apoio durante o atendimento psicológico, raramente, cumpre novas indicações de atendimentos especializados. (P5)
\end{abstract}

Dessa forma temos mais uma vez, o resgate do trabalho familiar, e a importância desse acompanhamento para a dinâmica das famílias, visto que com esta forma de trabalho o tratamento tem mais resultados e eficácia.

Quando questionadas a respeito das orientações que as famílias recebem em relação aos acompanhamentos dos filhos, temos o seguinte "a família deve participar ativamente do atendimento do filho, seguindo as orientações feitas pela psicóloga, com o objetivo de auxiliar no progresso da criança". (P2) 
Uma segunda opinião afirma que

o trabalho com os alunos com necessidades educacionais especiais não se concretiza sem que o profissional trabalhe junto à escola e a família do educando. No caso do CEMAP (Centro Educacional Municipal Psicopedagógico), percebo uma necessidade de maior capacitação dos profissionais das escolas e das famílias [...] (P1)

A família deve ser orientada em relação ao atendimento do filho, duração, o porquê dos atendimentos e quais trabalhos devem ser realizados, afinal, ela é peça ativa na construção de um atendimento seguro e eficaz, pois são os familiares que são responsáveis pelos alunos e que vão estar acompanhando-os durante os atendimentos e principalmente, em casa, ressaltando, portanto a importância do apoio familiar para o desenvolvimento dos alunos.

As psicólogas afirmam ainda que orientam aos pais quanto aos seguintes aspectos "como podem lidar com as dificuldades dos filhos, da importância de frustarem essas crianças, e de ensinar e educar sem dó. Mostrar o certo e o errado, e principalmente punir quando necessário". (P4) e "[...] orientar aos pais com relação à necessidade de seu filho, quando este precisa de acompanhamento psicológico; encaminhar a criança para os atendimentos médicos e paramédicos que se fizerem necessários; promover cursos de capacitação de orientação para pais na educação de seus filhos". (P1)

Muito importante esta colocação que a psicóloga traz, pois na literatura podemos buscar o que algumas autoras nos dizem sobre a importância de se educar os alunos com deficiências da mesma forma dos demais, caracterizando apenas suas potencialidades e limites.

$\mathrm{Na}$ visão das demais psicólogas são colocadas outras orientações, que também se fazem bastantes pertinentes ao trabalho com as famílias, a saber:

aconselho aos pais que: auxiliem os filhos durante os deveres de casa e participem das reuniões agendadas pela equipe pedagógica; não comparem o rendimento escolar dos filhos, pois cada um possui o seu ritmo de aprender; elogios sejam feitos mediante cada conquista dos filhos e que as falhas sejam vistas como possibilidades de aprendizado, reservem tempo para conversar com os filhos sobre suas dificuldades, principalmente, sobre as dificuldades escolares. (P3)

aceitar as limitações da criança; não tratá-las de modo diferente em relação aos outros filhos; desenvolver e reforçar suas habilidades; ter pulso firme; entender que a criança irá se desenvolver mas dentro dos limites dela. (P5) 
Todas as colocações são muito importantes, pois cada uma diz de pontos que devem ser considerados em relação à orientação às famílias; pois estas devem saber como lidar com o desenvolvimento do seu filho e acompanhar seu tratamento psicológico de perto, com a sua presença e apoio a criança se sente mais segura e confiante para seguir em frente e trabalhar suas habilidades e potencialidades.

\section{Os limites e as possibilidades da profissão}

Em algumas questões as psicólogas foram questionadas a respeito do seu ponto de vista sobre o processo de inclusão escolar dos alunos com deficiências, e de como avaliar tais aspectos. Umas visualizam a inclusão de forma positiva, já outras a vem como algo que ainda não acontece, sendo um parecer bastante relativo, uma vez que cada uma possui um tempo de experiência na profissão. Perguntamos ainda sobre os limites e as possibilidades que o psicólogo vem enfrentando neste processo, as respostas foram positivas e relação à literatura.

A percepção de uma das psicólogas a respeito do processo de inclusão escolar é a seguinte:

percebo de forma positiva, pois a inclusão de alunos com necessidades educativas especiais possibilita a construção de uma escola da qual todos façam parte em que todos sejam aceitos, ajudem-se e sejam ajudados pelos membros da comunidade escolar, apesar das dificuldades de eliminação das barreiras atitudinais, arquitetônicas, falta de recursos tecnológicos, capacitação dos profissionais e vontade política. (P1)

É muito forte a fala da psicóloga que diz de algumas dificuldades das instituições em se adequarem às exigências e necessidades de mudança para receber os alunos com deficiências, é necessário adaptação, que muitas vezes não acontece apesar das leis existirem e darem direitos a estas crianças de frequentar as escolas, muitas vezes algumas delas não se sentem acolhidas nos atuais modelos de escola.

Mas se levarmos em consideração que o processo de inclusão é algo bastante recente, visto que a Política Nacional de Educação Especial na Perspectiva da Educação Inclusiva data de 2007, a fala de outra psicóloga é relevante:

a inclusão é um projeto muito novo e como tal enfrenta dificuldades. Assim como uma mãe não está preparada para receber um filho com deficiência e irá aprender a lidar, educar, conviver, amar, este filho, a escola também procederá da mesma forma: irá crescer neste sentido junto com o aluno. (P4) 
As perspectivas a respeito da inclusão variam, e de acordo com uma das psicólogas a inclusão vem acontecendo, sim, só que de uma forma razoável, e acrescenta a necessidade da adequação e das mudanças no meio escolar:

a inclusão escolar está acontecendo de forma gradual. Atualmente, existem turmas com alunos portadores de necessidades educacionais especiais, porém ainda há muito que se caminhar, principalmente, no sentido da qualificação profissional. Há profissionais que ainda se encontram fechados para mudanças que a inclusão escolar exige. (P3)

Mas a psicóloga mais nova e com menos tempo de experiência não concorda e afirma que a inclusão ainda só acontece na teoria, vejamos:

essa inclusão ainda é teórica na prática os alunos ainda são excluídos, quando, por exemplo, o espaço físico da escola não é acessível, tão pouco $p$ professor vem capacitado. As crianças são cobradas como se não existissem Necessidades Educativas Especiais, porém o laudo médico torna o zero ou a nota vermelha em algo positivo, para aliviar a IDEB escolar. (P4)

Pensando de outra forma uma das psicólogas afirma que a inclusão vem acontecendo, só que de uma forma inadequada no meio escolar:

IDEB. A inclusão está acontecendo, mas muitas vezes, de forma inadequada, pois alguns profissionais não estão capacitados para atender as crianças com NEE. $O$ currículo, muitas vezes não é adequado para essas crianças. Estamos caminhando, mas temos muito que aprender. Integrar é diferente que é incluir! Estamos mais integrando os alunos na escola regular, que incluindo de fato. (P2)

Esta visão de inclusão é diferente da outras, pois não adianta como a psicóloga nos aponta somente colocar o aluno na escola, é de suma importância atualizar os recursos e os professores para receber e acolher estes alunos.

Assim, pensando nas dificuldades existentes na profissão, no trabalho com os alunos com necessidades educativas especiais, temos o seguinte apontamento "as principais dificuldades enfrentadas é a falta de apoio por parte da mesma e da escola". (P5)

Novamente temos a questão da importância da família no processo de inclusão escolar. Participar, levando a criança aos atendimentos somente, não é suficiente, é preciso dar apoio e aceitar as diferenças, dentro dos limites e das possibilidades de cada um, para uma melhor condução, pensando sempre nas possibilidades, e que cada um vai se desenvolver à sua maneira. 
A família, peça chave para o processo de progresso dos filhos, mesmo sendo, ativamente participativa, como colocado no início do capítulo, não assumem certas responsabilidades, como mostra a fala de uma das entrevistadas:

não é sempre que o apoio familiar é oferecido durante os atendimentos. Sem o apoio da família, o atendimento do aluno acontece de forma parcial. Não é sempre que a equipe da escola mostra-se aberta a seguir as orientações afinal para alguns profissionais é difícil sair da rotina que aprisiona e limita o processo de aprendizagem dos alunos que possuem necessidades especiais educacionais. (P3)

Porém, uma das entrevistadas é bastante otimista no seu trabalho e nos afirma que "não considero que haja dificuldades, mas necessitamos de maior tolerância para que o aluno possa ter tempo para responder adequadamente ao tratamento". (P2)

Nesta perspectiva questionando sobre os desafios que o processo de inclusão escolar traz a estes profissionais, obtivemos respostas significativas, desde falta de tempo até uma maior colaboração da escola.

disponibilizar sempre que necessário tempo e recursos para os atendimentos à psicologia educacional; fazer o mapeamento de atendimento psicológico de forma atender à demanda existente, conscientizar as famílias (pai e mãe) na educação adequada que precisam dispensar as crianças. (P1)

Um ponto importante também assinalado por uma das psicólogas se refere aos trabalhos que precisam ser desenvolvidos dentro das próprias instituições, "familiarizar as escolas com tal processo inclusivo bem como informar os pais e a criança incluída seus direitos". (P4)

Assinalam também dentro das discussões sobre os desafios pessoais que precisam ser superados "temos que aprender a lidar com as diferenças e ter tolerância com as pessoas portadoras de necessidades especiais". (P2)

A questão da escola, da sociedade e novamente dos pais e familiares aparecem mais uma vez como uma dificuldade:

a dificuldade é a promoção da inclusão deste aluno, conscientização dos pais e dos professores, da sociedade acerca das limitações da criança. A colaboração e a cooperação de todos é importante para que estereótipos e preconceitos sejam quebrados, e um ensino de qualidade seja promovido. (P5) 
O discurso sobre a necessidade de um sistema educacional que possibilite uma maior integração e inclusão destes alunos no ambiente escolar se repete na fala de outra das psicólogas entrevistadas

a necessidade de se construir um sistema educacional de qualidade para todos impõem uma forma de atuação diferenciada por parte daqueles que trabalham no campo da educação. A quebra de estereótipos e preconceitos, ponto de partida para a implantação de uma escola inclusiva, faz-se necessária para que o modelo que aí está se rompa. A colaboração e a cooperação entre todos os participantes do processo educacional (pais, professores, alunos, coordenadores pedagógicos, diretores, comunidade, etc.) na tentativa de mudar papéis e responsabilidades tornando o ambiente educacional mais flexível são alguns dos objetivos a serem alcançados neste processo. $O$ (a) psicólogo (o) na escola pode colaborar para que a inclusão aconteça de forma verdadeira atuando diretamente na elaboração de projetos pedagógicos que respeitem a diversidade. (P3)

Na fala da psicóloga é possível constatar que o psicólogo na equipe de profissionais de uma escola é sem dúvida importante, realizando trabalhos que fazem a diferença, trabalhando tanto com alunos, quanto com os pais e funcionários, mas ainda neste sentido, tais trabalhos foram questionados nas entrevistas, corroborando com o arcabouço teórico e metodológico, eis as respostas:

já realizei um significativo trabalho de implantação e implementação do Projeto Incluir na Rede das escolas regulares comuns estaduais, nas fases de expansão, monitoramento e avaliação da Educação Inclusiva, bem como realização de palestras para os pais e responsáveis pelos alunos. Atualmente atendo crianças com necessidades especiais no CEMAP de Santo Antônio do Monte. (P1)

são realizadas palestras nas escolas com temas relacionados à educação inclusiva. Participam dessas palestras: professoras, supervisoras $e$ diretoras. No Cemap, também, acontecem reuniões com as professoras e pais, sendo que, o objetivo principal é sanar dúvidas no que se refere às posturas a serem adotadas com os alunos que possuem necessidades educacionais especiais (várias dicas são passadas). (P3)

A partir das contribuições das psicólogas firmamos mais uma vez a real necessidade de se realizar um trabalho conjunto com pais, professores e sociedade para fortalecimento do processo de inclusão escolar dos alunos com deficiência. Pensando assim, em capacitação para o corpo docente e palestra e reuniões informativas aos pais, que já vem acontecendo, mostrando cada vez mais que o psicólogo pode fortalecer as escolas, neste processo. Mesmo sendo uma instituição que atua de forma integrada as escolas do município não podemos deixar de citar que ainda assim, a presença de um psicólogo em tempo integral nas escolas se 
faz necessário, para um acompanhamento contínuo dos grupos de trabalho e dos demais alunos.

no semestre passado o CEMAP foi até as escolas trabalhar o termo inclusão. Neste semestre temos na quinta-feira espaços abertos para receber pais/professores e também vamos até as escolas com palestras que abordam temas referentes às demandas recebidas no centro. (P5)

Sim. Realizo palestras nas escolas e orientação à pais e professores, sempre que se faz necessário. No CEMAP, temos um cronograma de palestras nas escolas e orientação à escola. (P2)

os professores, supervisores e diretores, bem como a família dos alunos incluídos são sempre convocados para orientações aqui no cemap. Porém. os demais funcionários da escola e pais tem uma vez por mês, palestras e discussão em grupo para orientação e informação, sobre política nacional inclusiva e saídas para enfrentar tal processo inclusivo. (P4)

Existe sim a necessidade de trabalhos que envolvam a capacitação dos professores e demais funcionários para com o processo de inclusão escolar, e essa forma de trabalho vem sendo felizmente realizada pelos profissionais que nela atuam, mesmo sendo uma amostragem pequena, percebemos que em algumas cidades este profissional consegue exercer um trabalho significativo, mesmo passando por certas dificuldades e preconceitos.

As reuniões com as famílias acontecem o que é bom e produtivo para os alunos e para seu progresso escolar, mas as capacitações necessitam de uma maior frequência da sua realização, visto que apesar de serem citadas como algo necessário ainda não foram de certa forma realizadas, se fazendo extremamente necessárias, dentro da perspectiva colocadas pelas próprias psicólogas sobre a existência de preconceito e o enquadramento de alguns profissionais em certos modelos estereotipados.

\section{Considerações finais}

A análise dos dados permitiu traçar importantes paralelos a respeito da atuação do psicólogo âmbito escolar, além de permitir reconhecer que este profissional está conquistando de forma singular o seu espaço no meio escolar, desenvolvendo, portanto, uma atuação condizente com a sua formação.

Ao lermos as entrevistas para a análise dos dados, foi possível perceber que trabalhos significativos vêm sendo realizados pelos psicólogos no município em questão, estes vem atuando cada vez mais no âmbito escolar, e auxiliando no processo de formação das crianças 
e dos jovens, realizam um trabalho significativo quando o assunto é inclusão de pessoas com deficiência na escola.

Um dos principais trabalhos desenvolvidos pelos profissionais da psicologia nas instituições escolares quanto à inclusão escolar, mostra a necessidade de atuação frente aos problemas escolares que estas crianças apresentam, e o psicólogo se faz presente e atuante, mostrando e reforçando, a pais, funcionários e educadores que o trabalho com estes alunos, e com os outros de certa forma, deve se pautar no desenvolvimento das habilidades e potencialidades de cada um, de acordo com aquilo que a criança tem de melhor, reforçar as habilidades e trabalhar com as limitações, buscando aprendizado e aperfeiçoamento.

Este trabalho reflete a crescente preocupação com a formação do psicólogo, que deve estar preparado para atuar em diversos âmbitos dentro de uma instituição, realizando trabalhos em equipe, capacitações, reuniões com pais e funcionários, e aperfeiçoamento constante, para desenvolver um trabalho efetivo e de qualidade a quem dele precisar.

Percebemos, a partir desta pesquisa, a necessidade de se promover ações que respeitam as diferenças e que fortaleçam os direitos humanos, priorizando ambientes acolhedores e humanizados de aprendizagem, para que as criança e/ou adolescentes possam se sentir seguros, acolhidos. Os trabalhos que visam fortalecimento da autoestima, e o desenvolvimento das suas potencialidades e habilidades pessoais também se mostraram importantes neste percurso.

Enfim, concluímos que o trabalho do psicólogo na escola vai além daquele trabalho voltado para as dificuldades de aprendizagem dos alunos, é um trabalho dinâmico que envolve todas as categorias do âmbito escolar, não fechando o círculo nos alunos, se a criança não aprende não é uma dificuldade somente sua, nem da escola, nem dos pais, o desenvolvimento requer uma postura dinâmica de ensino, que potencialize e atue com todas estas redes, pois tudo que perpassa a criança faz parte do seu desenvolvimento e são responsáveis pelo seu aprendizado.

Tendo em vista o tema pesquisado, percebemos ainda que o papel do psicólogo nas instituições escolares ainda é pequeno, não existindo em muitas instituições, o que desvaloriza um pouco a sua atuação. Esta pesquisa permite um passo inicial para suscitar novas discussões sobre a necessidade deste profissional na equipe escolar, mostrando e enfatizando seu papel, tanto nas linhas teóricas quanto na perspectiva prática. Esperamos que este trabalho possa contribuir para o desenvolvimento de uma linha de pesquisa em psicologia escolar/educacional, buscando mostrar a importante deste profissional. 


\section{REFERÊNCIAS}

BONI, Valdete.; QUARESMA, Silvia Jurema. Aprendendo a entrevistar: como fazer entrevistas em ciências sociais. Revista Eletrônica dos Pós-Graduandos em Sociologia Política da UFSC, v. 2, n. 3, p. 68-80, jan./jul., 2005.

HAGUETTE, Teresa Maria Frota. Metodologias qualitativas na Sociologia. 5 ed. Petrópolis: Vozes, 1997.

LAKATOS, Eva Maria.; MARCONI, Marina de Andrade. Técnicas de pesquisa. 3 ed. São Paulo: Editora Atlas, 1996.

\section{Como referenciar este artigo}

MIRANDA, F. D.; RIBEIRO, E. B. V. V psicologia e inclusão social de alunos com deficiência: a atuação do psicólogo na educação inclusiva. Doxa: Rev. Bras. Psico. e Educ., Araraquara, v. 20, n. 2, p. 133-149, jul./dez., 2018. e-ISSN: 2594-8385. DOI: 10.30715/doxa.v20i2.11409.

Submetido em: 28/05/2018

Aprovado em: 10/08/2018 